\title{
Razones poéticas en los umbrales de la Ilustración temprana. Desde los Fragmentos del ocio
}

\author{
Pedro Ruiz Pérez \\ Universidad de Córdoba
}

CES.XVIII, núm. 25 (2015), págs. 191-218. 


\section{RESUMEN}

Desde la segunda mitad del XVII hasta mediados del siglo siguiente se extiende una línea poética que trabaja con elementos persistentes desde la primera fase del barroco, pero con una articulación y un significado en que se perciben las huellas del cambio. Una de las líneas de esta estética bajobarroca representa un paso en la dirección adoptada después por la poética neoclásica e ilustrada, y puede concretarse en la reordenación de las relaciones entre sentimiento y razón. Este estudio toma como punto de partida el poemario anónimo Fragmentos del ocio (1668, reeditado en 1683), reconocido como de Juan Gaspar Enríquez de Cabrera, y, a partir de un análisis del empleo del término «razón» y su concepto, se apoya en las variantes de una diacronía que lo acerca al siglo XVIII para abordar una proyección de los rasgos observados en la caracterización de la poética bajobarroca. Se destacan como elementos distintivos un novedoso sentido de la inmanencia, la redefinición del lugar social de la poesía y de la posición de su autor y, finalmente, la tendencia a la poesía de circunstancias. Con ellas la sentimentalidad abandona su condición de componente definitorio de la lírica y abre paso a una racionalidad ligada a los nuevos modelos de sociabilidad e ideales expresivos.

Palabras clave

Enríquez de Cabrera, Fragmentos del ocio, razón, bajo barroco, poética, campo literario.

\section{AbSTRAC}

Since the second half of the seventeenth century a poetic current is developed until the middle of the next century, working with persistent elements from the first phase of the Baroque, but with a joint and a meaning where the traces of change are perceived. One line of this bajobarroca aesthetic represents a step in the direction that the neoclassical and illustrated poetry take after, and it may be materialized in the restructuring of the relationship between feeling and reason. This study takes as its starting point the anonymous book of poetry Fragmentos del ocio (1668, reprinted 1683), whose author was Juan Gaspar Enriquez de Cabrera. From an analysis of the use of "reason" and its concept, the study is based in the variants in a diachrony that brings the work near the eighteenth century. So, it is possible to map out the features observed in the characterization of the low baroque poetic. They are outstanding categories a new sense of immanence, the redefinition of the social place of poetry and of position of the author, and, finally, the tendency to the poetry of circumstances. With them, the sentimentality leaves his condition of essential component of lyric and gives way to a rationality linked to new models of sociability and expressive ideals.

KEYWORDS

Enríquez de Cabrera, Fragmentos del ocio, reason, low baroque, poetics, literary field.

Recibido: 3 de junio de 2015. Aceptado: 14 de septiembre de 2015. 
Con las distintas alteraciones y modulaciones introducidas por los escritores barrocos, el modelo del discurso amoroso seguía siendo el del cancionero petrarquista ${ }^{1}$ cuando el siglo XVII caminaba hacia su ocaso. Tras su inicio manuscrito como rerum vulgarium fragmenta, la codificación bembiana en sus inicios legó al siglo XVI un modelo arquetípico, vinculado a unos moldes métricos genéricos, a la integridad de una historia sentimental y a la noción misma de unidad, resultante todo ello en una identificación de poesía y vida. La relación Francesco-Laura construía sobre la idealización de la amada la identidad del amante, sustentada en la práctica de una escritura convertida en espejo de la biografía, a la vez sentimental y social. Con el siglo XVIII ya en un horizonte cercano algo empieza a moverse en este modelo, tejiendo con los mimbres del legado petrarquista un discurso que comienza a mostrar sus desvíos, justamente a partir de los elementos que ponían de manifiesto la convencionalidad de los sentimientos y la concepción misma del poemario como imagen de una identidad cerrada sobre sí misma. Un buen ejemplo de ello lo encontramos en los Fragmentos del ocio, aparecidos en 1668 de manera anónima, aunque pronto reconocidos como obra de Juan Gaspar Enríquez de Cabrera, duque de Medina de Ríoseco y Almirante de Castilla, último mayordomo mayor de Felipe IV y caballerizo mayor de Carlos II, hasta su muerte en $1691^{2}$. Frente al humanista profesionalizado en el cultivo de la filología y afirmado en su identidad por

1 Puede servir de referencia en este sentido el acercamiento de Gregorio Cabello Porras, Barroco y cancionero: el «Desengaño de amor en rimas» de Pedro Soto de Rojas, Universidad de Málaga, 2004.

2 Fragmentos del ocio que recogió una templada atención sin más fin que apartar estos escritos del desaliño, por que no los empeorase el descuido ordinario de la pluma en los traslados. El volumen aparece fechado en1668, pero sin indicación de lugar y taller de impresión, como en un refuerzo de la voluntad de anonimato. Muy pronto, sin embargo, la atribución fue clara y consignada en los márgenes de las portadas o en notas indiciarias de de procesos de lectura; en ellas se apoyan Salvá para su catalogación bibliográfica y Narciso Alonso CoRTés en su estudio pionero, recogido en su Miscelánea vallisoletana (Cuarta serie). Valladolid, Imprenta del Colegio de Santiago, 1926.

Nacido en 1623, nuestro poeta pertenece a la generación siguiente a la de Calderón y suma a sus cargos palatinos una relevante red de relaciones culturales y literarias. Su ayo fue el erudito Tamayo de Vargas, como reflejan las páginas del volumen, y cruzó poemas con Francisco López de Zárate, Luis de Ulloa y Pereira y Agustín de Salazar y Torres; destaca también su mecenazgo para con el pintor Juan de Alfaro, hermano del poeta Enrique Vaca de Alfaro. 
medio del verso, estamos ahora ante un noble amateur $^{3}$, que disimula su nombre quizá menos por el despego que la época mantenía aún frente a la impresión de los versos líricos que por la ausencia de la necesidad de afirmarse más allá de su privilegiado puesto social y una genealogía en la que no faltaban precedentes en la afición por el verso. La referencia en el título al emergente concepto de ocio en el escenario social sanciona esta posición, reafirmada por una apelación a lo fragmentario y disperso más cercana a la disolución del modelo sentimental y lírico del Canzoniere que a la imitación de la primera denominación en lengua latina de la obra de Petrarca. Pero no era esta la única separación del modelo ya en declive.

Un primer indicio aparece cuando el autor decide reeditar su obra, en $1683^{4}$, manteniendo en líneas generales su estructura y la caracterización tipográfica, pero introduciendo cambios de cierta entidad, desde la alteración en el orden interno de las composiciones y la sustitución de algunas de ellas. En este proceso un cambio aparentemente más sutil o menor se convierte en una mina demoledora en el edificio de la sentimentalidad petrarquista. En un número considerable de los sonetos que pasan de una a otra edición, entre otros cambios de diferente entidad, se produce el desplazamiento de Casandra, como nombre de la destinataria de una parte sustancial de los poemas, por Leonida. Las hipótesis sobre las razones del cambio pueden situarse en distintos planos: desengaño amoroso o aparición de una nueva amada, simple ajuste por razones fonestilísticas u ostentosa exhibición de la convencionalidad de sentimientos y amadas poéticas. La resultante, en cualquier modo, se sitúa en las antípodas del amor único y sublimador concebido y textualizado por Petrarca, desplazando al sentimiento del lugar de centralidad ostentado en el discurso lírico precedente, aun después de los avatares barrocos y la apuesta gongorina por que «se diga y no se sienta». La dualidad de nombres femeninos, quizá de amadas, relativiza para los lectores atentos el papel del objeto de los sentimientos en la economía poética ${ }^{5}$, pero también el del propio sujeto de la sentimentalidad, que con la permuta onomástica revela su condición de orfebre del verso, más

\footnotetext{
3 Sigo el concepto desarrollado por Javier Jiménez Belmonte, Las «Obras en verso» del príncipe de Esquilache. Amateurismo y conciencia literaria, Woodbridge, Tamesis, 2007.

4 El nuevo volumen mantiene exactamente el título y reitera la ausencia de datos bibliográficos, reducidos a la mención del año.

5 He dedicado otros artículos a este asunto, desde los inicios del petrarquismo en España hasta su disolución. Véase Pedro Ruiz Pérez, “"No siendo sino para mujeres”: modelos poéticos, filografía y lectura en Boscán», Studia Aurea, 7 (2013), págs. 61-82 (http://studiaurea.com/article/view/v7-ruiz); «De Solís a Lobo: la mujer en la poesía bajobarroca», en Perspectives on Early Modern Women in Iberia and the Americas: Studies in Law, Society, Art and Literature in honor of Anne J. Cruz, ed. Adrienne L. Martin y M ${ }^{\mathrm{a}}$ Cristina Quintero, New York, Escribana Books, 2015, págs. 490-501; y «Deidades apeadas: un nuevo patrón de género», Arte nuevo, en prensa.
} 
que de amante rendido al desahogo de la confesionalidad. Aun vinculada a los restos de la retórica amorosa, la poesía apunta hacia otros caminos, cada vez más distante en su consideración y lugar social de los que ostentara en los dos siglos anteriores. Unas décadas después, la propuesta de certamen recogida en la Guirnalda poética ${ }^{6}$ se convierte en el indicio significativo de un cambio. Ahora la mujer se ve apeada de su pedestal de amada y se convierte en mero objeto del discurso deliberativo, y en el marco de un juego competitivo se plantea una quaestio propia de un debate intelectual: «Diose por asunto general a los ingenios dijesen a quién hay más razón de querer: a una dama bonita y necia o a una discreta y fea, en veinticuatro coplas de romance. Competencia en que lucieron discretamente agudos, logrando coronar sus sienes de las desdeñosas ramas, para eterna memoria». De nuevo, el desplazamiento de la mujer en el papel de amada real y la correspondiente liberación de la sentimentalidad propician el juego, como confirma el que intervenga en él incluso un chico de catorce años, quien no habla con la voz de la experiencia, sino con la máscara del juego. A ello hace referencia la mención a la agudeza, ya ligada a la burla, y el matiz de la discreción, que la reduce a las leyes de la cortesanía, alterando la semántica y el valor de dos conceptos tan netamente gracianos y, por ende, barrocos. En el arranque de la cedulilla que reglamenta la competición vemos brillar la palabra «razón»; ciertamente, estamos aún lejos de las luces encendidas por los enciclopedistas y consagradas en la filosofía kantiana, pero bien podemos ver en todo ello los signos de una deriva, de un lento desplazamiento desde las posiciones altobarrocas y la poética vinculada a ellas.

El marco en que se inscriben estos procesos, entre lo social y lo poético (si no es más preciso hablar de la poesía y su sociabilidad), ha sido analizado en su perspectiva general europea ${ }^{7}$, en lo tocante a lo que se constituirá como modelo de referencia en las prácticas socioculturales y su proyección en un modelo estético $^{8}$ y en la concreción hispana de la deriva de la sentimentalidad en las prácticas mundanas ${ }^{9}$. El gran cambio en la mentalidad, ligado a la revolución científica y a la última remodelación del Antiguo Régimen en un escenario europeo cada vez más interrelacionado, ha sido analizado en términos de crisis de

6 Guirnalda poética, tejida de las más fragrantes flores que ha producido la fertil Carpentana Atenas. Academia seri-jocosa que se celebró en esta corte el día 22 de noviembre de 1733. Dala a la estampa don José Rodríguez, quien la dedica y consagra a mi señora doña María Nicolasa Rodríguez de los Ríos, marquesa de Casapontejos etc.. En Madrid, s.i., s.a.

7 Paul Hazard, La crisis de la conciencia europea (1680-1715), Madrid, Alianza, 1988.

8 Benedetta Craveri, La cultura de la conversación, Madrid, Siruela, 2003. Las manifestaciones hispanas se estudian en Mechthild Albert (ed.), Sociabilidad y literatura en el Siglo de Oro, Madrid, Iberoamericana, 2013.

9 Carmen MarTín Gaite, Usos amorosos del dieciocho en España, Madrid, Siglo XXI, 1972. 
conciencia. Sin incurrir en determinismos teleológicos, la atención a los avatares de estas décadas proporciona una perspectiva de interés para la consideración de los procesos subsiguientes, sobre todo en relación a algunos conceptos definitorios y generalmente incardinados en paradigmas opositivos, requiriendo, por ello, un acercamiento matizado, si no para recomponer su génesis, sí, al menos, para acercarnos a la delimitación del punto en que una noción pasa a adquirir su condición emblemática de una época, como ocurre con «la razón». Tras los estudios pioneros de François Lopez en este campo ${ }^{10}$ y las aportaciones valiosas realizadas en su seguimiento ${ }^{11}$, la conceptualización de la «época de los novatores» ha confirmado su pertinencia y mostrado su operatividad para un acercamiento matizado a una ilustración tan peculiar como la española y los valores que en ella intentaron su despliegue ${ }^{12}$. En nuestro caso, desde la concreta perspectiva del discurso poético, hemos planteado una noción algo más amplia en su cronología y más específica en cuanto a su alcance, fundamentalmente estético, pero que coincide con la más consagrada en la abolición de la frontera del siglo y del cambio dinástico como elemento significativo, en la consideración, por tanto, de un período con un pie en cada centuria, atendiendo a su especificidad no en términos de ruptura, sino de desplazamientos en distinto grado de significación distintiva ${ }^{13}$. Al usar para su designación el rótulo de «bajo barroco» pretendemos recoger la dualidad de unos vínculos con una raíz que proporciona muchos de los componentes del entramado ideológico-estético, pero también la distancia que comienza a marcarse justamente desde la conciencia del insuficiente valor del modelo altobarroco para la conceptualización de un mundo en cambio, finalmente desembocante en la «edad de la razón». Si

10 François Lopez, «Los novatores en la Europa de los sabios», Studia Historica, 14 (1996), págs. 95111; y «La vida intelectual en la España de los novatores», Dieciocho, 20 (1997), págs. 78-89.

11 Jesús Pérez Magallón, Construyendo la modernidad: la cultura española en el «tiempo de los novatores» (1675-1725), Madrid, CSIC, 2002; y Alain BÈGUe, Alain y Jean Croizat-Viallet (eds.), La literatura española en tiempos de los novatores (1675-1726), monográfico en Criticón, 103 (2008).

12 Vale aquí el concepto aplicado por Pedro Álvarez de Miranda (al que habremos de volver) en Palabras e ideas: el léxico de la ilustración temprana en España (1680-1760), Madrid, RAE, 1992.

13 Como resultados del proyecto de investigación Poesía hispánica en el bajo barroco (repertorio, edición, historia), FFI2011-24102 del Plan Nacional de Investigación Científica, Desarrollo e Innovación Tecnológica, hemos tratado de establecer una conceptualización a través de distintas obras colectivas: Ignacio García Aguilar (ed.), Tras el canon. La poesía del Barroco tardío, Vigo, Academia del Hispanismo, 2009; Pedro Ruz Pérez (ed.), «Tardos vuelos del Fénix». La poesía del bajo barroco, monográfico de Calíope. Journal of the SRBHP, 18,2 (2012); e Itzíar López Guil, Adrián J. SÁez, Antonio Sánchez Jiménez y Pedro Ruiz Pérez (eds.), Heterodoxias y Periferias: La Poesía Hispánica en el Bajo Barroco, monográfico de Versants. Revista Suiza de Literaturas Románicas, 60,3 (2013). Véase también la página web del proyecto, http://uco.es/phebo/. De manera paralela, el Centro de Estudios de la Literatura Española de Entre Siglos (siglos XVII-XVIII) ha desarrollado una amplia serie de estudios sobre el período, consultables en su mayor parte en su página web, http://celes.labo.univ-poitiers.fr/es/. 
cabe situar la plenitud de este momento en la segunda mitad del siglo XVIII, la consideración de procesos sin saltos y una diacronía sin fronteras artificiales nos lleva a considerar una cronología más amplia y a acercarnos a procesos ya bastante consolidados en la segunda mitad del siglo XVII, para lo que puede ser de gran utilidad observar algunos cambios entre dos momentos en estas décadas.

Volvamos, pues, a los Fragmentos del ocio que nos sirvieron de punto de partida con su llamativo planteamiento editorial (reedición incluida) y las alteraciones en este proceso del nombre de la dama, relacionados sin duda con la pérdida del equilibrio entre sentimentalidad y expresión, capital en la poética precedente. Su abandono representará uno de los legados más determinantes que el bajo barroco transmitirá a la poética dieciochesca que desemboca en el neoclasicismo y la ilustración. Antes de llegar a estas consideraciones, se impone la necesidad de un análisis más preciso de los textos, tomando como eje el uso de la palabra «razón» y las modulaciones que refleja en el espacio intermedio, híbrido, entre lo afectivo y lo ideológico.

Atendiendo en primer lugar a lo cuantitativo, llama la atención la abundante presencia del término en las composiciones recogidas por nuestro aristocrático autor. En casi un tercio de los romances que conforman el núcleo de la parte del volumen, la segunda, dedicada al octosílabo aparece el vocablo «razón». Hablamos de 22 de las 76 piezas, y la proporción se hace más significa si tomamos en consideración que en su mayor parte se trata de sátiras burlescas (a partir de la inicial clave jocosa) o composiciones líricas con estribillo, modalidades genéricas poco propicias para colocar lo razonable como clave. Un ejemplo vale para mostrar la conciencia de esta realidad en la propia voz lírica, así como para justificar una perspectiva diacrónica y comparatista a partir de la reedición. Se trata del romance «Respeto y amor batallan» (f. 46; f. 74) ${ }^{14}$, con una declaración tan explícita como la de este cuartete: «No es de mi amor la armonía / de aquella música ciega, / que pierde las consonancias / cuando la razón la templa». El verso inicial plantea, en una variante léxica, el conflicto entre razón y sentimiento, y, en clave genérica, el primer elemento del par aparece con una valencia negativa frente a la identidad entre afecto y musicalidad. La desaparición de la mencionada estrofa en la versión reeditada más cerca del

14 Salvo indicación precisa en otro sentido, cito por la edición de 1668, indicando el número de folio. Por la facilidad de acceso a un ejemplar de la Österreich Nationalbibliothek digitalizado en internet (http:// books.googleusercontent.com/books/content?req=AKW5Qaeq6dnOMDlvoOPkBTGv5pSLwGBiQh4SoW6 DzFqxCVLaqUFudDQPVwpAwfDhX8bHN8s3nHHVMhW0gJxlh1vj_dS0nnThhRNDhz31IhzLSTC64wnMymgDvmnLvp0hUogXx3Of7Vd_G4Z6DIXQhpfINqy5leQhSwluyI9FdYkteOe2q9YmB5bNY7gsOkpD9fCVIUbR38fhCeGPyTaQfnG00UCO04V_fDMVWEovTjnleKL8cSVql3_Lhbmm-yXjaEKiDNHt4beu5ktiKc3j6nxgDjAGlqiv7A) incluyo también la localización del poema cuando aparece en 1683, lo que también permite percibir los cambios en la dispositio. Modernizo grafía y puntuación. 
final de siglo, en el contexto de un profundo proceso de reescritura del romance, bien podría indicar un cambio en la consideración del concepto y una recomposición de los valores a él ligados. Baste este indicio para apuntar una línea metodológica en correspondencia con lo extendido de la práctica en Enríquez de Cabrera, antes de centrar el análisis en un corpus con manifestaciones más precisas.

Si de los romances (y sus peculiaridades) pasamos a los sonetos (y las suyas), encontramos datos más relevantes en número y cantidad. Acorde con uno de los modelos más reconocibles en las décadas precedentes, los Fragmentos del ocio se abren con una serie de sonetos dominados por los asuntos amorosos, y este elemento mayor de la dispositio no se altera de la edición de 1668 a la de 1683. Sí lo hace la estructura interna del bloque, que pasa de 33 a 35 piezas e introduce en ellas una fuerte reorganización, paralela a la reescritura de bastantes de estas piezas y el sustancial cambio en el nombre/perfil de la dama. En este proceso, el uso del término «razón» gana en relevancia, pasando de 18 recurrencias (casi el 55\% del corpus en la primera edición) a 21 (un 60\% 15 años después); de la serie inicial desparecen algunos sonetos, dos de ellos con el término en cuestión, lo que indica que en las incorporaciones o reescrituras la presencia del vocablo (y su referencia) se intensifica y gana en relevancia. La atención al contexto convierte estos datos aritméticos en algo aún más significativo. Una consulta a la utilísima herramienta del CORDE nos proporciona un cuadro revelador, sintetizado de esta manera ${ }^{15}$ :

\begin{tabular}{|ccc|}
\hline Fechas & Registros & Documentos \\
\hline $1651-1655$ & 788 & 38 \\
$1656-1660$ & 298 & 27 \\
$1661-1665$ & 161 & 20 \\
$1666-1670$ & 104 & 18 \\
$1671-1675$ & 127 & 14 \\
$1676-1680$ & 306 & 12 \\
$1681-1685$ & 170 & 16 \\
\hline
\end{tabular}

La generalizada y sorprendente tendencia regresiva permite algunas matizaciones, en parte importante relacionadas con la poesía. Así sucede con las 34

15 Real Academia Española: Banco de datos (CORde) [en línea]. Corpus diacrónico del español. <http:// www.rae.es> [última consulta realizada, 29 de mayo de 2015] 
recurrencias del término que acumulan los Ocios de Rebolledo, en su edición de $1660^{16}$, o la importante presencia en los registros de los debidos a sor Juana Inés de la Cruz, Ana Abarca de Bolea o Vicente Sánchez, lo que apunta en su conjunto a que el léxico ligado a una noción significativa avanza antes en el campo de la poesía que en el de las ciencias o la filosofía, lo que podría ser una explicación al declive en su uso, cuando el debate se resuelve en el verso mientras no queda recogido en los otros géneros. Por otro lado, lo escurridizo de la cuestión en términos estrictamente cuantitativos se vuelve a mostrar si atendemos a los datos relativos al lustro inicial del período novator, justamente cuando se produce una pequeña inflexión que prepara el repunte de los años siguientes. Al iniciarse la década de los 70 el CORDE muestra en sus registros dos presencias tan significativas y dispares como la de José Zaragoza, matemático astrónomo y cosmólogo convertido en referencia para los primeros novatores, y la de Miguel de Molinos, con un tratado tan señalado como su Escala mística: entre la ciencia y el quietismo, la razón se erige en referencia común, por más que los años fueran amortiguando su importancia ${ }^{17}$. Y cuando esto ocurre, en la década en que la aplicación académica registra una reducción a la mitad de las referencias, la reedición de los Fragmentos del ocio da cuenta de una intensificación del término en la obra, devolviendo a la poesía una cierta posición de vanguardia en la atención a este concepto en pugna por un lugar de relevancia.

Otra consideración lexicográfica nos ayuda a avanzar en matizaciones sobre el contexto cronológico e ideológico antes de atender con cierto detenimiento a los textos de los Fragmentos del ocio. No contamos en relación a este concepto con la valiosa aportación que el estudio lexicográfico de Álvarez de Miranda, ya citado, ofrece para otras nociones clave en la ideología del período; las muy escasas referencias al uso de «razón» se limitan a la relación que se establece entre el concepto y las ideas de entendimiento e ilustración (pág. 187), al paralelismo con el valor de utilidad en una obra del novator Juan de Cabriada (pág. 303) y a la contraposición que, entre otros, establece Feijoo entra razón y opinión (pág. 578). La definición de «razón» en los diccionarios entre los siglos XVII y XVIII muestra en sus variaciones, si no una proyección de un cambio sustancial en su importancia, una voluntad de matización, posiblemente indicativa de la preocupación por perfilar el sentido de un concepto con síntomas de cambio en

16 Se trata de la segunda edición (tras la princeps de 1650), la usada en el CORDE. En esta cronología, el volumen acapara algo más del $10 \%$ de las recurrencias registradas. Por lo fácilmente apreciable, no me detengo en los paralelismos establecidos entre este título y el de Enríquez de Cabrera, así como en la condición nobiliaria que unía al Almirante de Castilla con el conde de Rebolledo, señor de Irián.

17 Unas calas en el CORDE para los quinquenios correspondientes en el siglo XVIII muestran unos datos muy parecidos a los registrados para el período 1676-1680. 
su valor semántico y social. Las escuetas referencias en los repertorios de Covarrubias y Rosal $^{18}$ se centran en unos campos semánticos de radio reducido, ceñido, en los términos del diccionario manuscrito a «discurso, plática y cuenta», que el Tesoro precisa como 1) facultad de discernimiento y juicio, 2) expresión y 3) lo ceñido a lo justo o exacto. Un siglo después el diccionario académico (1726-1739) multiplica las acepciones y da cuenta de la complejidad alcanzada por el término, incluyendo algunas utilidades propias de la vida práctica más codificada, como la representada por el comercio; así, en diferentes entradas, Autoridades registra los significados de «potencia intelectiva», "acto del entendimiento o discurso», «equidad en las compras y ventas», «cómputo, cuenta o número», «orden y método», «justicia en las operaciones» y «voz o palabra que explica el concepto», antes de recoger una importante variedad fraseológica. En esencia, y a partir de las comunes apelaciones a la raíz latina de ratio, la mayoría de las acepciones giran en torno al doble sentido de iudicium, que apunta al criterio y a la justicia, con el sentido de equilibrio como elemento aglutinador. Estamos, pues, muy lejos del valor que identificaba el concepto con la crítica demoledora, con el escalpelo destinado a poner en cuestión la realidad y la axiología heredadas. Más bien persisten aquellos elementos que tienen que ver con los principios dominantes en una mentalidad clásica, sin solución de continuidad entre lo ideológico, lo ético y lo estético.

Este telón de fondo de movilidad cuantitativa y cualitativa del concepto permite ubicar mejor el tratamiento específico que recibe en nuestro texto, de manera más específica, en el corpus de sus sonetos, comenzando por los de la aparición más temprana, a las puertas del período novator. De manera un tanto previsible, la referencia aparece en las composiciones más cercanas a lo político, ideológico o, sencillamente, moral, y así ocurre en los sonetos contiguos (ff. 17v y 18; ff. 10v y 12) dedicados «Al inglés que degollaron por haber muerto a otro inglés, que había sido cómplice en la muerte de su rey» y «A la corte», respectivamente, donde afirma que «en ti no nos da ejemplo la justicia / que en la razón se ignora el escarmiento» y que en la Babilonia cortesana se halla «perdida la razón a explicaciones». La idea de renuncia al escarmiento podría prefigurar reflexiones ilustradas sobre el régimen pènitenciario y su sentido punitivo, aunque sin abandonar un tópico de honda raíz barroca. Ambos extremos esbozan la dimensión compleja del concepto en estos años situados entre dos regímenes ideológicos. Sin embargo, un análisis centrado en la recurrencia de la

18 Sebastián de Covarrubias Orozco, Tesoro de la lengua castellana o española, Madrid, por Luis Sánchez, 1611; y Francisco del Rosal, Origen y etimología de todos los vocablos originales de la lengua castellana, ms. 6929 de la BNE. 
noción de «razón» en las composiciones «amorosas» resultará más productivo, por el número y variedad de estas y porque permite acercarnos al par que la razón forma con el sentimiento.

Siguiendo las acepciones delimitadas en Autoridades es posible ordenar la práctica totalidad de los sonetos y recomponer un discurso de la razón de lo estrictamente amoroso a una dimensión más abarcadora. Así, comenzamos por la consideración como «acto del entendimiento o discurso», presente en una composición de aire circunstancial: «Habiéndose retirado una dama, quejosa sin culpa del autor» (f. 19; f. 13); en ella responde a las quejas y la actitud femenina que «en mi razón alivios de esperanza / culpan el tribunal y el sufrimiento», donde las referencias forenses en clave metafórica revelan el sustrato retórico, discursivo, con que se contempla la relación, pretexto para una declaración en términos de razonamiento ${ }^{19}$.

Cabe mencionar aquí dos valores no recogidos sensu strito en el diccionario académico, pero presentes en el uso de nuestro autor. Es el caso del uso del término con sentido de causa o motivo, tal como aparece en el soneto en el que «Asegura su voluntad a una dama que le dijo juzgaba que podía faltar» (f. $14 v$ ), cuando declara a la interesada que «vive» «en mis pasiones la razón de amarte», convirtiendo la dicotomía en una paradoja que aúna pasión y razón, entendida la primera como debilidades del alma del amante, y la segunda en términos de causa o motor, en este caso, de un amor que no se identifica con la pasión. En términos de respuesta podría establecerse aquí la relación con otro sentido no explicitado en Autoridades y que acerca la razón a un valor más dieciochesco, al identificarla con cordura; así ocurre en el soneto en que «Prueba que sólo su amor consigue el atributo de dios fabuloso, y no el que se emplea mal» (f. 7; f. 4v): frente al delirio y «de amor las sinrazones», aspira a una versión del amor que se emplea bien, basado en «la razón de las acciones», que se sitúa en clave divina; la idea de «acierto» surge del triunfo de las «finezas» sobre las «ceguedades».

De nuevo en el conjunto de acepciones académicas, la idea de «justicia en las operaciones» (o las intenciones) se manifiesta en el soneto (f. $7 \mathrm{v}$; f. 9) con el rótulo «Acusando la incredulidad de una dama y contentándose con la razón de su afecto»: afirmándose en la «fe constante», el amante sostiene que la «impiedad» de la dama «ofende la razón, no la castiga». La impiedad se identifica con la sinrazón y la injusticia, que en la dama toma forma de incredulidad; frente

19 Con esta denominación se rotulaban editorialmente algunas piezas oratorias de genera distinta, tanto demostrativo como deliberativo o judicial. Valga citar los «razonamientos» de Pérez de Oliva en la edición póstuma de sus Obras por Ambrosio de Morales (Córdoba, por Gabriel Ramos Bejarano, 1586). 
a ella, la firme convicción del amante en la justicia de sus «pasiones» y de sus «acciones» se manifiesta en una razón que en este caso, como señala el título, permite la conciliación con los afectos. De este modo en otro soneto, donde «Disculpa no haberse muerto de enamorado» (f. 9; f. 6), la solidez nacida de unas justas pretensiones se traduce en triunfo, incluso en el desdén, ya «que es vencedora mi razón vencida». La armonía es aun mayor cuando el valor de la dama, alabada por su «mérito», la hace partícipe de este principio, aludiendo a «la razón con que mueves mis acciones» (f. 16).

En esta vía la noción se vinculará a valores de mesura y equilibrio, de una estabilidad expresada en la definición académica de «orden y método»; si en los Fragmentos del ocio no encontramos un desarrollo directo de esta idea, la podemos percibir en negativo, por todo lo que encierra la imagen contenida en el soneto inicialmente rotulado «A unos celos» (f. 13) y que se presenta con un rótulo más detallado en la segunda edición: «A unos celos de que se quejó Belisa» (f. 19v). No es el único cambio; en 1683 la defensa del amante (reprochado por Belisa) se basa («vivirá mi razón tan ignorada») en una noción identificable con la señalada en el párrafo previo. No ocurría lo mismo en la princeps, en que la dirección de los celos es la inversa, y ahora el enamorado, que ha perdido por este sentimiento su equilibrio, afirma de manera desgarrada que «todo un volcán en mi razón enciendes»; la potente imagen de ascendencia barroca ${ }^{20}$ apela a lo telúrico, a lo que irrumpe sin cauce ni control desde lo subterráneo y oscuro, en un estallido que traduce en destrucción la violencia y desmesura, como antítesis de una razón marcada por lo luminoso y mundano, por una equilibrada serenidad. En perspectiva, la variante de reescritura (y volveremos sobre ello) supone una sustitución de la imagen negativa y agria (bien que de poderosa fuerza expresiva y sentimental) por una positiva pero discreta afirmación basada en el menosprecio de todo lo que suponga exterioridad, lo ajeno a la propia razón: «Pero tú, en las disculpas empeñada, / ignoras que aun te acusa la defensa. $/$ ¿No ves que en ti da voces el delito?».

Finalmente, esta referencia nos conduce al sentido más englobador de «razón», definida como «potencia intelectiva». Como tal, la definición es válida por igual para la epistemología de base aristotélica y para la perspectiva de los librepensadores ilustrados, incluidos los protagonistas del pensamiento libertino $^{21}$. Y en la escala de matices que lleva a conceptos diametralmente opuestos, el texto de Enríquez de Cabrera nos abre una iluminadora ventana

20 Véase Ramón Andrés (ed.), Tiempo y caída. Temas de la poesía barroca española, Barcelona, Quaderns Crema, 1994.

21 Véase Iris M. Zavala, Clandestinidad y libertinaje erudito en los albores del siglo XVIII, Barcelona, Ariel, 1978. 
a estos cambios, y justamente en aquellos poemas que se presentan con una vocación definitoria en torno a los afectos y pasiones. Al tratar la «Difinición de celos» (f. 14; f. 17) el soneto presenta este estado como aquel «donde está la razón tan limitada / que juzga la ignorancia del acierto / y arriesga la verdad el desengaño», con claras implicaciones epistemológicas (y morales) de lo que supone la distorsión introducida por algo que nubla la capacidad intelectiva y de discernimiento. Sin llegar al extremo de ofuscación que representan los celos, el sentimiento amoroso mismo se presenta como causante de unos desarreglos cognoscitivos identificados (en amplia tradición) con la ceguera, ya desde que apareciera iconográficamente la venda de Cupido; así se muestra de manera muy notoria en un soneto recogido exclusivamente en la edición de 1668 (f. 15 v), bajo el rótulo «Difinición de amor», donde este aparece como una «ciega razón», con expresión tan rotunda como inequívoca y un tanto plana; no ocurre lo mismo en otra «Difinición de amor» que sí pasa a la reedición (f. 20v; f. 19v), donde el poeta acude a la imagen de «mandar a la razón cada sentido». La formulación tiene el trasfondo de anatemas religiosos y condenas morales, pero también recoge, en una cronología más específica, ecos o, al menos, coincidencias con los postulados cartesianos y su rechazo del demonio que puede nublar el pensamiento y torcer el recto camino de la razón. En una proyección que muy posiblemente supera las intenciones y aun los planteamientos conscientes del noble versificador, el sintagma encierra el gran debate filosófico e intelectual de la segunda mitad de siglo, con la doble y divergente raíz de la modernidad, basculante entre el valor de la experiencia y el de la racionalidad. El primero servía de base a las teorías sensistas y a la cada vez más potente corriente empirista, más atenta a lo individual y consiguientemente a las formas de la sensibilidad y aun la sentimentalidad. Con base en la segunda se mantenía una tradición de pensamiento más cercana al aristotelismo en su aspiración a la generalidad de lo universal, donde la lógica abstracta sustituye a los concretos movimientos anímicos. La vinculación del empirismo al ámbito anglosajón, protestante y capitalista, y la del racionalismo a la tradición continental, católica y rentista, le dio al debate intelectual una dimensión sin duda muy alejada del horizonte latente en los Fragmentos del ocio; no obstante, la mera concurrencia de los dos conceptos en un estrecho sintagma aparece como sintomática de un escenario en que la razón se movía en busca de una definición precisa y un lugar en la construcción ideológica de un mundo cambiante.

Esta perspectiva general, más abarcadora que analítica, confirma la variedad de modulaciones con que la razón aparece en el discurso poético-amoroso del volumen, aun cuando quedan fuera de los tanteos de Enríquez de Cabrera algunas de las acepciones propuestas en Autoridades, sobre todo las que tienen 
una dimensión más material y alejada de la práctica nobiliaria, como la relativa a la «equidad en las compras y ventas» o el «cómputo, cuenta o número». La profundización en algunos casos particulares y hacerlo a la luz del cotejo de las dos versiones ofrecidas sucesivamente por el autor permiten acercarse a una lectura más profunda del sentido de la razón y, por lo que interesa a su dimensión estética, la que resuelve una parte de la polisemia del término en la acepción de «voz o palabra que explica el concepto», esto es, el espacio en que lo ideológico se convierte en formal, que bien puede ser una definición del poema. La lectura en espejo de tres sonetos facilitará esta perspectiva complementaria. Ofrezco las reproducciones de las ediciones disponiendo siempre a la izquierda la página de la princeps, señalando la foliación cuando no aparece reproducida.
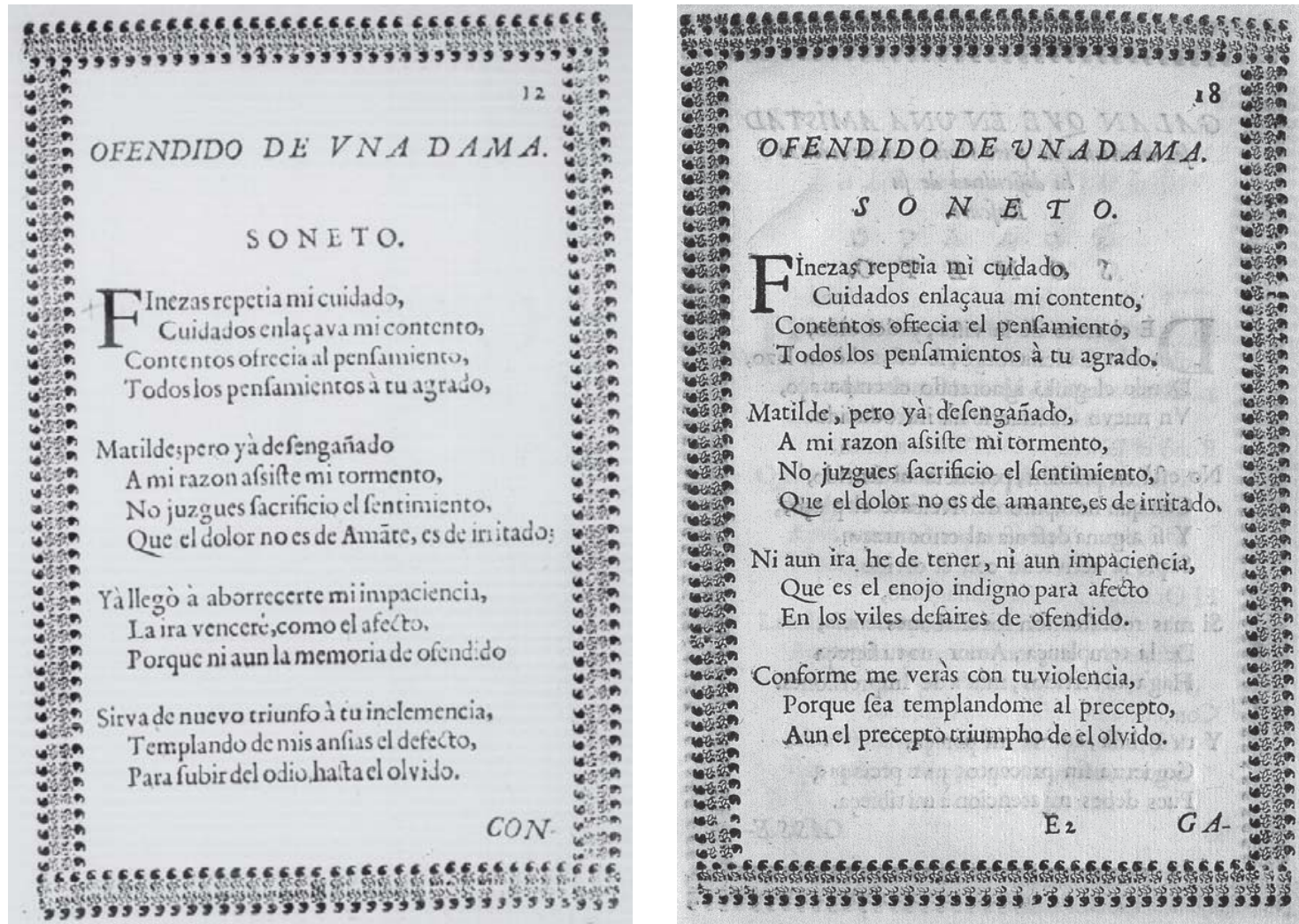

Junto a la corrección del error del v. 3, resultante sin duda de la compleja trama establecida sobre encadenamientos y paralelismos semánticos y sintácticos, la edición de 1683 introduce una profunda modificación en el texto, que, como en un significativo número de casos, se concreta en la sustitución de los tercetos. El mecanismo es interpretable como la persistencia de unos planteamientos y la modificación de las conclusiones en el lapso de los quince años transcurridos entre las dos apariciones del poema. Antes de entrar en los cam- 
bios y su significación, hay que señalar que estos no afectan en absoluto al verso donde aparece la referencia a la razón, en una posición casi exacta de centralidad en el poema. La reiteración subraya la pertinencia de la dualidad «razón» y «tormento», en una relación sintáctica entre la noción barroca de desengaño y la moderna consideración de la experiencia, ahora subordinando los afectos y pasiones a la razón, incluso convirtiéndolos en una vía a una doble consideración de lo razonable como justo y como un estado de serenidad. La coincidencia textual y la compartida base de sentido solo pueden resolverse en las divergencias planteadas por la reescritura de los tercetos. La versión 1668 se centra en la figura de la belle dame sans merci, de raíz caballeresca y cancioneril, a partir de la noción de inclemencia, en rima con «impaciencia» para establecer el eje de relaciones femenino-masculina; de ella el amante sólo puede salir venciendo sus pasiones (afecto e ira), aunque lo haga con la finalidad fundamental de no concederle un nuevo triunfo a la tirana, buscando en el olvido la superación del odio. Quince años después se introducen cambios de notable trascendencia, en una reelaboración de versos y conceptos que gana en tensión con el mantenimiento de la mayoría de las palabras en rima; el primer cambio supone un desplazamiento de la semántica ligada a la tópica crueldad de la amada por un término de valor más general, «violencia», en cuyo vencimiento se empeña el amante, pero no por la conversión del amor en odio (el término ha desaparecido en 1683), sino por una voluntad de apartarse de cualquier elemento de tensión, de desequilibrio. Precisamente, el segundo cambio («precepto» por «defecto») supone una reiteración del término en el verso siguiente y marca la orientación del desplazamiento. El sema negativo de la referencia inicial es sustituido por algo que apela a un orden, a una razón formulada en términos de norma, de ley. Se trata de una regla de vida de remota base neoestoica por lo que tiene de situarse por encima de las pasiones, desdeñadas ahora más que vencidas y tomando como horizonte, en el centro del terceto final, una templanza establecida como ideal. El triunfo sobre la vileza de algunos sentimientos permite aspirar a un horizonte de dignidad personal identificable con el triunfo de la razón (templanza, olvido) sobre las pasiones generadas por los sentimientos fuera de los preceptos.

En este caso los cambios tienen un reflejo inicial (y una guía para el lector) en la alteración del título, y así se sustituye la generalización inicial por una precisión que refleja la posición del autor y cuestiona la omnipotencia del amor, que mantiene sus rasgos de divinidad, pero puede verse enfrentado, para relativizar sus efectos, por la razón, cuya referencia solo aparece en 1683. De nuevo los tercetos, en este caso el final, se convierten en el marco de los cambios textuales y del giro en el significado del poema. En su segunda redacción 
f. $11 \mathrm{v}$

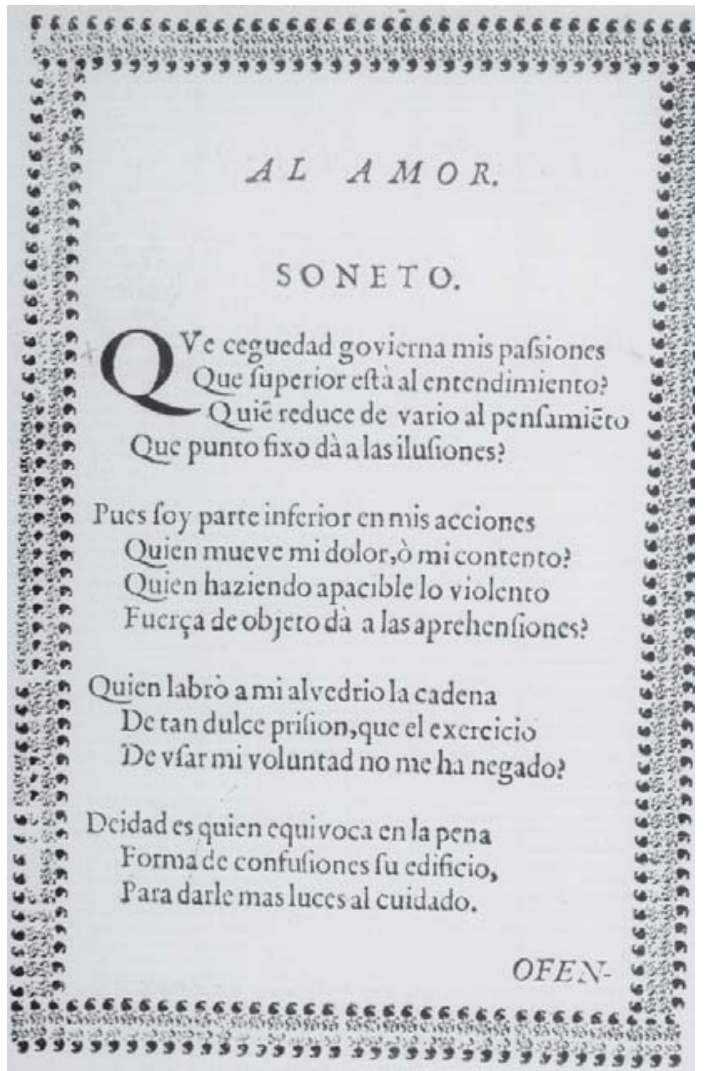

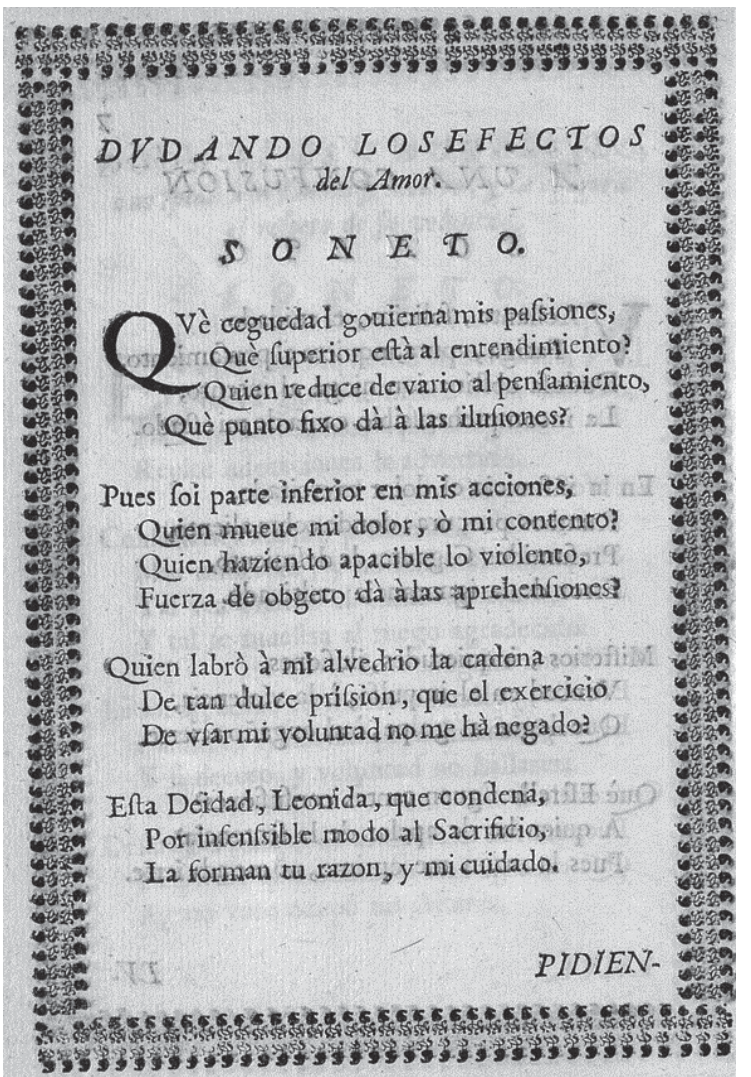

el soneto parte de la tensión entre los elementos confrontados por las primeras palabras en rima, pasiones y entendimiento, y, entre interrogaciones denotadoras de perplejidad y una cierta vulnerabilidad, el conflicto se proyecta (sin cambios de una a otra versión) hasta el final del primer terceto, concentrando en los tres versos finales una resolución que cambia de signo en la redacción final. En 1668 se impone la imagen de la divinidad todopoderosa y tiránica, que impone confusiones y cuidado. En 1683 la aparición explícita de la dama, como destinataria del poema y del «cuidado» del poeta, pone la condición del amor a una altura humana, y lo sobrenatural es sustituido por una consideración de orden personal; la deidad, al identificarse con actitudes del amante y de su objeto amado, queda apeada a un plano más propio de la psicología, de los movimientos del alma en los personajes implicados en la acción amorosa, confrontando el «cuidado» del amante con la «razón» de la amada, con lo que cobra cuerpo una noción inexistente en la primera redacción. La bimembración del verso final marca una oposición que, en juego de simetría, proyecta de manera condensada y en cierta forma invertida la tensión desplegada en los dos versos iniciales. En este caso «razón», en su concreta disposición sintagmática (atribución a una 
dama desdeñosa y polaridad con «cuidado») pierde connotaciones positivas, con un sentido de «orden», pero tiránico, que desplaza el entendimiento por las cuitas; esto justifica identificar con una divinidad la potencia del amor, sin perder de vista que no se trata de un agente externo, sino de la consecuencia del poder de una y la debilidad de otro, del triunfo de una razón despótica sobre lo que podría identificarse con el entendimiento.
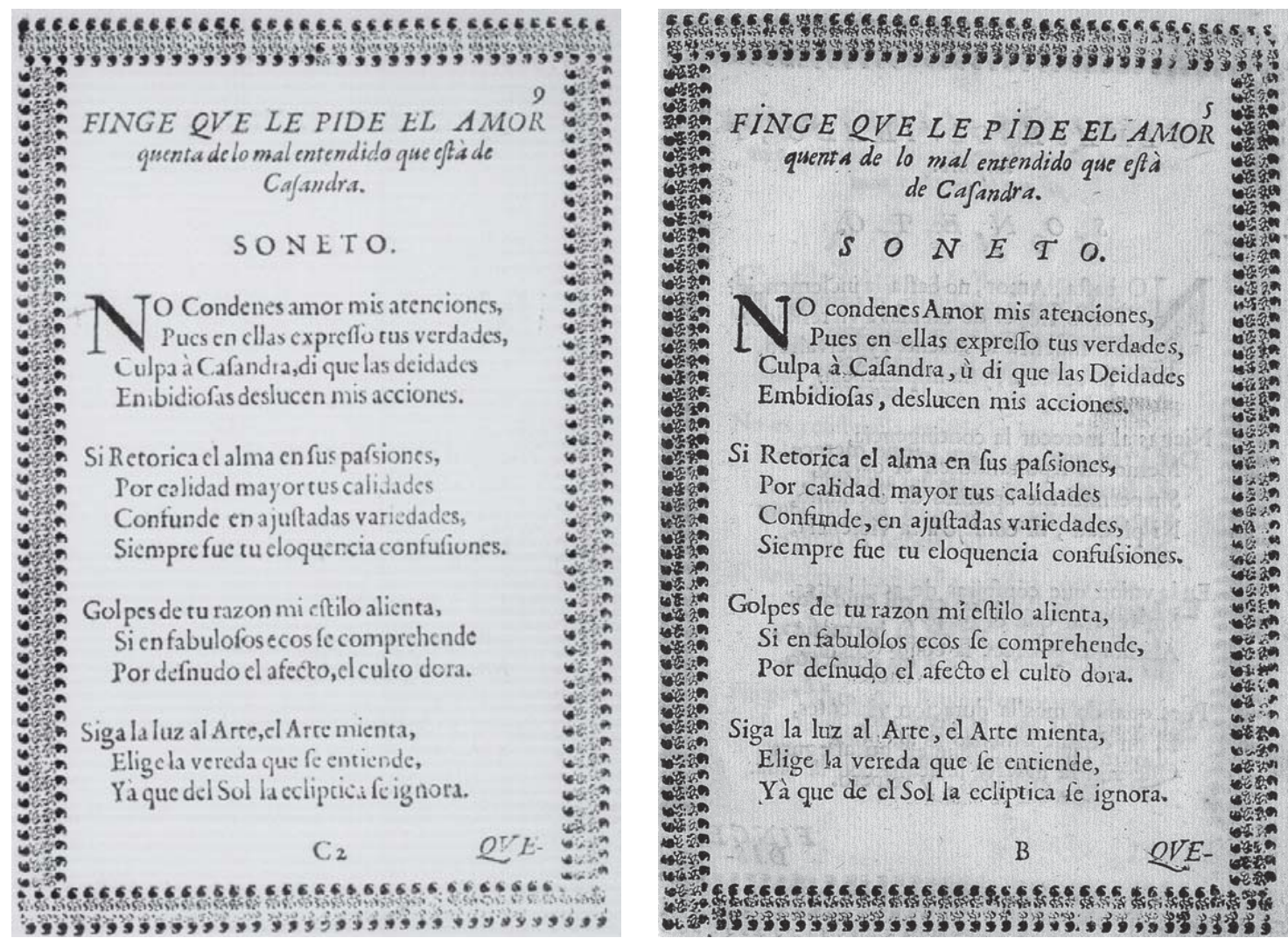

En este caso $^{22}$ la variante (v. 3) puede ser una corrección de errata, por la omisión de la disyuntiva. Sea eso o una modificación de lo originalmente escrito, el resultado no deja de tener significación, ya que, al plantearse como una disyunción, separa a la dama, con su posible responsabilidad, de los designios de las divinidades en su intervención en contra del amante. Más que oposición, esta alternativa vendría a subrayar la idea de indiferencia, porque en el segundo cuarteto aparece el verdadero asunto, al colocar el amor en términos de lenguaje, poniendo en posición de rima sus efectos (pasiones y confusiones) y unos rasgos (calidades y variedades) que pueden invertirse en su valor, ya que son objeto de una regla razonada, la retórica, aquí opuesta a una expresión

\footnotetext{
${ }^{22}$ Hay un error en la foliación, que duplica el f. 9. En este caso, debería ser f. 10.
} 
desatada, presentada como elocuencia. Justo a continuación, para iniciar los tercetos, aparece un sintagma paradójico, casi un oxímoron, si no fuera por la señalada polisemia de «razón». Los «golpes de tu razón», entendidos como los efectos negativos del orden (o desorden) amoroso, se presentan como resultado de un estilo, que es el comportamiento del amante, pero también el tono de su expresión, con lo que el soneto entra de lleno en una dimensión metapoética, de manera más precisa, en una consideración del amor en términos de lenguaje, en su análisis como una convención («finge» avisa el rótulo), que puede, por tanto, ser reducida a términos de razón. Con la marca de la rima, los versos de los tercetos se emparejan en un triple paralelismo, a partir de la referencia al estilo, que podemos leer en términos de un programa poético que trasciende la mera temática amorosa de la poesía para situarse en términos de razón, no la que golpea desde la tensión erótica, sino la que se presenta como un camino o vereda orientada al entendimiento. Esta lectura convive y se complementa con la articulada en un eje de simetría, que empareja entre sí los versos 9 y 14, de un lado, y 11 y 12, de otro, siempre sobre el par inalterable formado por los versos 10 y 13. Si leemos en clave de paralelos, el aliento del estilo descubre su condición ficcional y, contra el fondo de los golpes de la razón amorosa, desmonta las claves de un programa poético, en el que se anticipan, desde una base neoplatónica y retórica, los que se convertirán en principios clave en la ilustración y el neoclasicismo. Así, el arte se presenta a la vez con las marcas del orden, la claridad y la razón, pero desde la conciencia de su mentira, con ecos del soneto de uno de los Argensola sin sus dosis de moralidad («es tanta la beldad de su mentira», «lástima grande / que no sea verdad tanta belleza»). Algo de ello sí aparece en el verso en simetría; en el 11 la construcción en quiasmo plasma la violencia de las contraposiciones: en el centro pugnan el afecto, los sentimientos, y la cultura, la razón, tensándose en los extremos entre la desnudez y el adorno, en línea con un debate poético que atraviesa el siglo XVIII y no se resuelve (relativamente) hasta finales de la centuria siguiente. De nuevo en el eje paralelo de la rima, este significativo verso enlaza con el final, de velada paradoja: de un lado apunta a un léxico científico, en clave de razón matemática y proyección cosmológica, y de otro, con el refuerzo de la posición final y el contraste de rima con «dora», se asume la imposibilidad de conocimiento, pues siempre hay algunos arcanos resguardados en la ignorancia. Es en este marco en el que se apunta, sin la estridencia de una posición de relevancia, la que parece la propuesta más coherente y que opone a la razón que golpea la razón que encamina y ordena. La «vereda que se entiende» conecta, ciertamente, con la llaneza y claridad erigida como estandarte en la batalla anticultista de las décadas previas, pero también apunta a una forma 
de entendimiento identificado con lo racional, con la voluntad que irrumpe en la revolución científica y su proyecto de someter la naturaleza a las leyes del orden matemático. A distancia de la grandiosidad de los descubrimientos surgidos del uso del telescopio y el cálculo numérico, se apunta la humildad de la vereda, la falta de pretensiones de trascendencia de un camino que sólo aspira al entendimiento y que por ello puede ser compartido, ya que, lejos de los «ecos fabulosos», aparece la palabra real (por más que «el arte mienta») que no «comprehende», sino que es entendida. Podríamos hablar a la vez de un programa poético y de un programa amoroso, y encontraríamos en ello la confirmación de los estrechos vínculos entre ambos en el desplazamiento desde la expresión sentimental a la construcción racional, desde la estética (y la sentimentalidad) de las pasiones a la que se orienta a unos modos de razón que tienen mucho que ver con la conquista de una distancia, por el alejamiento de la sublimidad (la de lo trágico, la del grito desgarrado, la de la desmesura, también ornamental) en camino (o vereda) a la comunicación, al arte de la conversación, que pasa del XVII francés al XVIII español, tal como consagrarían Villarroel, Lobo o Benegasi.

$$
* * *
$$

La variedad del uso de «razón» en el léxico y la axiología de Enríquez de Cabrera y sus modulaciones en la diacronía que se acerca al XVIII muestran desde la lectura planteada una doble tendencia que unifica este rasgo conceptual. De una parte, se aprecia una confluencia hacia la consideración de estos procesos en términos de formulación estilística, de caracterización del discurso. De otra, y en estrecha vinculación, la emergencia del valor de la razón se vincula a la superación de los sentimientos y pasiones como clave de la definición humana y la formulación poética. El análisis confirma la distancia que resta para que estas consideraciones alcancen el significado de la razón estrictamente ilustrada, y no solo en términos cronológicos, ya que bajo la deriva léxica apreciable en los Fragmentos del ocio laten inesquivables residuos de la mentalidad escolática. Sin embargo el edificio ideológico del antiguo régimen comienza a mostrar en sus grietas los signos de una paulatina descomposición. Una de las minas que zapan los cimientos se muestra en nuestro poemario en los procesos de humanización, que empezamos a apreciar en las consecuencias del desdoblamiento del nombre de la dama. De la onomástica el lector pasa a la ontología, y en el desdoblamiento se enfrenta a la disolución del arquetipo, a la relativización del símbolo, a la atención a lo individual. ¿Qué hay de Casandra a Leonida? La articulación del pensamiento en los versos de Enríquez 
de Cabrera mantiene algo de la lógica del silogismo, pero se aparta ya de la abstracción universalizante característica del escolasticismo, empezando a definir una atención por lo singular, que no hay que confundir con lo biográfico o confesional. Se trata más bien de la aplicación del emergente principio científico de la observación de lo concreto, de la experiencia sin apriorismos. De ahí el desplazamiento desde la mera casuística escolástica (renovada por los jesuitas y su hegemonía en el sistema formativo) al interés por los matices, a la consideración de la variedad.

Bajo los múltiples rasgos con que la razón se perfila en el poemario late un generalizado predominio de la semántica ligada a la pérdida o la aspiración aún inalcanzada. Los sintagmas en que se inscribe el término reiteran esta impresión: «razón vencida»; «ofende la razón, no la castiga»; «la razón me oprime, no me advierte»; «todo un volcán en mi razón enciendes»; «donde está la razón tan limitada»; «perdida la razón a explicaciones»; «a mi razón asiste mi tormento»; o «derribó la razón de mi escarmiento». En este sentido, como se apuntaba al principio, se mantiene una línea de continuidad con algunas claves de la poética precedente, pero introduciendo en ella los elementos del cambio. Entre el secretum y el concetto, encarnados en la simbología del laurel y su correlato en la figura de Laura, el petrarquismo asentó su dominio a partir de la vinculación de una poética a una filografía. La proyección del animismo se tradujo en un ideal de transparencia, que en el plano del estilo se tradujo en términos de naturalidad, de la sencillez derivada de la sprezzatura, por más que en todo este edificio regía un valor de trascendencia: el amante buscaba un iter mentis ad Deum y el poeta perseguía la corona del reconocimiento; para ambos el poema era el espacio de la sublimación, donde, por la vía de la espiritualización, los sentimientos se transmutaban en materia estética, y desde ella el autor construía su identidad personal, afirmaba un nombre, una imagen y una biografía interior. Desde la arquitectura del soneto en el canzoniere y los efectos de su secuencia hasta la rima, todos los elementos estructurales de esta poética se conjuntaban en el sostenimiento de su edificio conceptual. En ello jugaba un papel fundamental la persistencia de unos sustantivos abstractos (sufrimiento, tormento, lamento, escarmiento... $)^{23}$, ligados a unas pasiones y dispuestos en el poema para mantener, con la trabazón de un silogismo, un universo de valores, un conceptismo establecido como puente entre el de la lírica cancioneril cortés y el codificado por Gracián, eslabonando la poética entre las décadas iniciales del siglo XV y las finales del XVII. Los ejemplos traídos de los Fragmentos del ocio muestran la

23 Véase Juan Manuel Rozas, «Petrarquismo y rima en -ento», en Filología y crítica hispánica. Homenaje al profesor F. Sánchez Escribano, Madrid, Alcalá, 1969, págs. 67-86. 
persistencia de algunos de estos elementos, pero también la diferencia derivada del avance de nuevas nociones, ligadas a cambios de orden más general en la cronología establecida.

La propuesta de Góngora sintetizada, «más a lo moderno», en elevar lo burlesco a categoría estética ${ }^{24}$ abre una solución de continuidad en el devenir de la poética de raíz petrarquista y, aunque con cierta lentitud, se extiende hasta alcanzar un alto grado de generalización a lo largo de la segunda mitad del siglo XVII y convertirse en la poética dominante en el cambio de siglo, sin una frontera efectiva en lo aleatorio del calendario o el impacto histórico de un cambio de dinastía. Frente a la sublime trascendencia del modelo previo se levanta un edificio de inmanencia y jocosidad, acorde con el horizonte mundano que se extendía desde Francia y que se desplegaba en protocolos académicos y juegos de salón, entre la burla y el chichisbeo ${ }^{25}$. Seguimos aún lejos de la razón ilustrada de orden kantiano, pero también se alejan los elementos de la cosmovisión barroca y su orden de valores; también de su poética. Sin incurrir en el reduccionismo de considerarla una época de transición, nos encontramos con un momento que, sin dejar de ser barroco, se decanta en una dirección que nos orienta, como queda adelantado, a considerar las ideologías y las estéticas consideradas como paradigmáticas de los siglos XVII y XVIII menos en términos de corte epistemológico que en los de un progresivo desplazamiento, con elementos destacados que sirven de puente entre dos modelos. La que Paul Hazard categorizó como la época de la «crisis de conciencia» europea tuvo en España sus particulares manifestaciones, pero estas no se desgajaron por completo del movimiento continental, como se percibe en lo relativo al movimiento novator, y este no fue el único nexo de conexión con lo que ocurría en la Francia del preciosismo, en la Italia de Metastasio o en la Inglaterra donde se asentaba el empirismo. Entre la razón cartesiana y un sentimentalismo que partía de un sensismo de base empirista y se resolvía en el encumbramiento de la sensibilidad, en el paso del XVII al XVIII Europa vive las tensiones que se harán características del «siglo que llaman ilustrado». Las contradicciones han de estallar en las contradicciones de una razón que cede al paso al romanticismo. Antes, la dialéctica se asienta en el período que llamamos bajo barroco, cuando, entre otros, empiezan a alterarse los equilibrios establecidos entre razón y sentimiento, y, con el esce-

24 La inicial propuesta de Robert Jammes es desarrollada de manera sistemática por Antonio PéreZ Lasheras en diversos estudios; véase, en particular, Más a lo moderno (Sátira, burla y poesía en la época de Góngora), Zaragoza, Anexos de Tropelías, 1995; y Ni amor ni constante (Góngora en su «Fábula de Píramo y Tisbe»), Valladolid, Universidad de Valladolid, 2011.

25 Remito de nuevo a las monografías de Craveri, La cultura de la conversación, y MarTín Gaite, Usos amorosos. 
nario privilegiado de la poesía, ambos valores entran en una dinámica sobre la que se sostiene el paso del alto barroco a los valores estéticos e ideológicos de la segunda mitad del siglo XVIII en España.

La ya clásica monografía de Joaquín Arce ${ }^{26}$ trató de resolver la complejidad del panorama poetico dieciochesco por la vía de una taxonomía de base estructuralista, por lo opositivo, estableciendo un paradigma de categorías que, en su lectura más simple, se presentaban aisladas y disociadas entre sí, además de apartadas del devenir cronológico. En lo que toca a la primera mitad del siglo, desarrollada en realidad sin solución de continuidad con lo observable en las décadas precedentes, nociones como las de «barroquismo», luego extendida a «rococó», comportan una connotación negativa y menor, entre las exageraciones epigonales y un mero formalismo decorativo que no llega a cuajar, además de plantear una oposición radical con lo «ilustrado» y «neoclásico», abiertos, por otro lado, con el punto de fuga del «prerromanticismo». La segmentación, que acaba fijándose en una tópica visión de etapas, tiene una clara utilidad clasificatoria y ordenadora, aunque la multiplicación de líneas de frontera da en una parcelación excesiva y en una fosilización de la dinámica histórica, al margen de la heterogenidad derivada de la alternancia de criterios estrictamente formales y de carácter ideológico. Desde esta perspectiva, por ejemplo, sería muy difícil la categorización de una poesía como la analizada en estas páginas, y no se podría explicar su conexión con la desplegada entre Rebolledo y sor Juana, en los límites de la segunda mitad del siglo XVII, o los citados poetas dieciochescos, del otro lado. Lo observado en los Fragmentos del ocio al hilo de su tratamiento poético y conceptual de la noción de «razón» podría servir de indicativo de algunos rasgos que mantienen su centralidad durante casi un siglo, entre la Paz de Westfalia y la llegada al trono español de Carlos III, entre la muerte de Quevedo y la de Lobo, entre la Agudeza y arte de ingenio de Gracián y los Orígenes de la poesía española de Velázquez. Baste un ejemplo tomado del corpus de la poesía octosilábica y jocosa, con su tratamiento de las relaciones amorosas, para ver el concentrado de componentes, su significación específica y sus elementos de conexión con la estética poterior. Me refiero al romance «Con la metáfora del juego, habla en su amor, elige a Leonida, dejando a Menga». Sin salir del rótulo topamos con el juego conceptista de la metáfora, la pervivencia del código del naipe ${ }^{27}$, la mezcla de lo culto y lo popular en la onomástica de las damas y

26 Joaquín Arce, La poesía del siglo ilustrado, Madrid, Alhambra, 1981. No es el momento de detenerse en las revisiones de sus propuestas en la crítica reciente, que ha matizado y actualizado sus conceptos.

27 Son de imprescindible consulta las monografías de Jean-Pierre Étienvre, Figures du jeu: études lexico-sémantiques sur le jeu de cartes en Espagne (XVI'-XVIII siécles), Madrid, Casa de Velázquez, 1987; y Márgenes literarios del juego: una poética del naipe, siglos XVI-XVIII, Londres, Tamesis, 1990. 
la misma alternancia entre ellas, regida, como veremos, por reglas que tienen menos que ver con los afectos que con la razón o, sencillamente con el juego, como clave en una nueva sociabilidad alejada de la sublimidad de las pasiones, entre el amor único o el sentido de la honra. En uno de sus cuartetes el poeta sintetiza: «Terciaba Menga en el juego, / mi vista en Leonida atenta / quizo pasar al cuidado / y se descartó de Menga». El léxico del naipe articula y connota los versos y les da su tono lúdico, el que caracteriza por igual las relaciones entre los sexos y la práctica de la poesía. Se trata de dominar el azar por medio de unas reglas precisas, como se dominan los afectos por medio de una razón, por muy incipiente o débil que esta sea. Cuando el juego renuncia a su componente burlesco, pero mantiene lo que tiene de artificiosidad, como ocurre en los sonetos, el reajuste en la nómina de damas y su misma variedad se muestran como la faz más visible de un reordenamiento de mayor profundidad, resultado de un programa más o menos consciente para racionalizar la sentimentalidad, para reducir las pasiones por medio del análisis, rebajando su fuego aun a costa de una impresión de frialdad o el coqueteo con la trivialización. Sin salir del marco de este volumen, es lo que Antonio Sánchez Jiménez señala como «musa casera» de Tafalla y Negrete o el desplante que Ignacio García Aguilar analiza en Torres Villarroel, en los dos casos en textos editados en el siglo XVIII. Décadas antes se imprimía el romance de Antonio de Solís «Despidiéndose de una moza, en vulgaridad» con los mismos rasgos, los de una interposición de recursos de distanciamiento para subvertir la sentimentalidad ligada al arrebato amoroso y para derivarla a unos modos expresivos, a un estilo poético, de muy distinta temperatura al de la ortodoxia petrarquista y su reelaboración altobarroca. Baste recordar su cuartete de cierre: «Y así, Inés, por lo que pago / a tu falsedad y por lo / que a mí me debo, te dejo. / Allá vas, cómante lobos». Los casos citados, no casualmente, pueden servir para ejemplificar la deriva estética que hemos venido estudiando estos años y para acercarnos al grado en que la reordenación del par sentimiento-razón caracteriza la estética bajobarroca que pasa del siglo XVII al XVIII para dominar la estética de su primera mitad.

En la dinámica de continuidad y alteraciones que se sucede con los significativos hechos históricos, culturales y estéticos concentrados en el ecuador del siglo XVII, se puede distinguir una serie de rasgos que apuntan a las causas profundas de una estética con más espacio para la razón y las claves de su desarrollo a lo largo de un siglo. El impacto más o menos directo de la filosofía cartesiana y los efectos de la primera revolución científica, la postergación de los ideales imperiales y el relajamiento de la axiología ligada a la Contrarreforma y al lugar de centralidad de la metrópoli hispana, junto con las formas de sociabilidad florecientes en Europa, singularmente en Francia, se traslucen 
en una disolución del sentido de la trascendencia, en la reubicación del papel social de la poesía y la posición de su autor ${ }^{28}$, y en el desarrollo de una poesía que se sitúa entre la expresión de la intimidad y la celebración de los grandes eventos, dando un nuevo sentido al valor de composiciones de circunstancia. El auge de las prácticas del salón en una nueva definición de la cortesanía, de la que pueden dar cuenta de modo significativo los versos recogidos en los Fragmentos del ocio, cataliza y reúne todos estos factores ${ }^{29}$. Entre unos usos sociales en crecimiento a partir de principios del siglo XVIII y los nuevos aires franceses, la conversación y el juego marcan la práctica de la poesía, que vuelve a ostentar su valor de adorno del caballero, aunque sin excluir su función como vía de acceso a la sociabilidad del salón de quienes no lo hacen por la nobleza de su origen, sino por su virtuosismo con la palabra, hablada o escrita. El verso se erige en cauce reconocido y potenciado, en particular para el debate sobre la casuística amorosa o las bromas entre los contertulios. En este marco, de fingida imagen de confianza y cordialidad, no hay, sin embargo, espacio para la expresión auténtica de los sentimientos, siempre retenidos en los límites del buen gusto mundano. En el plano de las relaciones el cortejo, luego convertido en chichisbeo, desplaza a la pasión, por lo que la galantería se hace más un factor de palabras que de sentimientos, y, como muestra Enríquez de Cabrera en su reedición, aquellas son más fácilmente intercambiables que estos, por lo que en el poema (imposible saber si en el corazón del poeta) Leonida sustituye sin mayor problema a Casandra. La idea del amor único y fuente de la transformación espiritual por la vía de la idealización se diluye, dejando campo abierto a un paseo por las más intrascendentes anécdotas galantes, sin acercarse nunca

28 Téngase en cuenta el panorama trazado por Joaquín Áldvarez BarRiEnTos, Los hombres de letras en la España del siglo XVIII: apóstoles y arribistas, Madrid, Castalia, 2006. Véase también Joaquín ÁlvarEz Barrientos, François Lopez e Inmaculada Urzainqui, La república de las letras en la España del siglo XVIII, Madrid, CSIC, 1995.

29 En este punto marca una apreciable diferencia la prosa recogida en el volumen, mucho más apegada a modelos de ocio cortesano o de intervención en el entorno regio propios del período anterior; así se aprecia en las «Reglas de torear», subtituladas «Preceptos de una opinión», que abren el volumen de 1668 o en los dos textos que aparecen en su clausura: «Este papel se dio al rey, nuestro señor, don Felipe Cuarto, un año después de la muerte de don Luis Méndez de Haro, su primer ministro, por la turbación que se aumentó en el gobierno, solicitando algunos introducirse en el grado que tenía, como por los motivos de desorden que se continuaban» y «Este papel se dio a la reina, nuestra señora, doña Mariana de Austria, tutora y gobernadora en la menor edad de Carlos Segundo, con el celo de una buena introducción en sus primeros pasos, sin pasar a mayores motivos, por no confundir las resoluciones que tocaban a las primeras reglas»; en 1683 el volumen se cierra con las «Reglas de torear». Véase Santiago Martínez Hernández, «Fragmentos del ocio nobiliario. Festejar en la cultura cortesana», en Bernardo J. GARCía y $\mathrm{M}^{\mathrm{a}}$ Luisa LoBato (coords.), Dramaturgia festiva y cultura nobiliaria en el Siglo de Oro, Madrid, Iberoamericana, 2007, págs. 45-87, aunque recordando que los versos de Enríquez de Cabrera están más cerca de la sociabilidad descrita por Craveri para el ambiente mondaine en Francia. 
a la constitución de una historia amorosa de verdadera relevancia. Con este paso, se agranda la apertura temática, dando paso a situaciones más cotidianas y cercanas, pero ya sin el tono satírico que generalmente tenían en el período altobarroco. A la inversa ocurre con la epístola, que abandona la caracterización moral y se convierte en el instrumento privilegiado de la comunicación amistosa, incluso de los episodios más triviales ${ }^{30}$. Como las aspiraciones humanas, la poesía se acerca a ras del suelo, hasta dar en el tono casero señalado en los textos de inicios del siglo XVIII, incluso cuando una guerra por la posesión del trono está sacudiendo a la Península. Lejos de la trascendencia, entre lo satírico y lo moral, emerge el valor de lo jocoserio ${ }^{31}$. En los Fragmentos del ocio se manifiesta aún con una separación propia de etapas precedentes, distribuido por mor del decoro entre la aparente seriedad de los sonetos y el jugueteo de las composiciones octosilábicas. Lo que se generaliza, en cambio, es la fusión de los dos componentes en una nueva categoría, que también tenemos que considerar en clave estética, por más que no alcance la altura de la poesía burlesca de Góngora. No obstante, bastaría volver sobre el propio título de Enríquez de Cabrera y el señalado juego de sustitución de los nombres femeninos para intuir cuánto hay de juego y entretenimiento en estos poemas, colocándolos en el más neto plano de la inmanencia de una práctica sin ninguna pretensión de sublimidad.

Pese a la falta de noticias documentales, no resulta difícil situar la mencionada práctica en el marco del salón cortesano, desde la propia condición social del autor y aun el empleo del anonimato formal para dar sus libros a la imprenta $^{32}$. La jerarquía del Almirante de Castilla lo distancia de la comercialización del libro, ya que no necesita acudir a la publicación para ganar dinero, protección o nombradía. De otro lado, esta posición lo sitúa en un bien definido marco sociocultural, identificable con el salón cortesano, teatro de ga-

30 Véase Pedro Ruzz Pérez, «La epístola poética en el bajo barroco: impreso y sociabilidad», en Poésie et societé en Espagne: 1650-1750, coord. Jean-Marc Buigues, monográfico del Bulletin Hispanique, 115.1 (2013), págs. 221-252; y su edición de José Joaquín BenEgasi, Composiciones epistolares, Madrid, Clásicos Hispánicos, 2012; también «Benegasi y la poética bajobarroca: prosaísmo, epistolaridad y tono jocoserio», Cuadernos de Ilustración y Romanticismo, 20 (2014), págs. 175-198. http://revistas.uca.es/index.php/cir/article/ view/1989/1869.

31 Véase Jean-Pierre Étienve, «Primores de lo jocoserio», Bulletin Hispanique, 106.1 (2004), págs. $235-252$.

32 Un ejemplo de transmisión parcial puede ser significativo del carácter de esta poesía y su metamorfosis entre la realización oral y la fijación impresa. El villancico «Zagales del Manzanares» aparece rotulado en la edición de 1668 como «Difinición de amor, en redondillas con estribillo, por que se puedan cantar las que se eligieren», y la difusión musical queda registrada por Mariano LAmBEA y Lola Josa (eds.), La música y la poesía en cancioneros polifónicos del siglo XVII. IV. Libro de tonos humanos, vol. III, Madrid, CSIC, 2005, pág. 43. El ejemplar R/22882 de la BNE muestra abundantes correcciones manuscritas en el texto. En 1683 el título se reduce, eliminando definitivamente las referencias al canto, el texto se corrige y las variantes empiezan desde el verso inicial, «Zagalas de Manzanares». 
lanteos donde las damas se alternan lejos de cualquier forma de compromiso o de vinculación más allá del juego. Es el marco propicio para el despliegue de la galantería y del ingenio como un componente esencial de la misma. Junto con el dominio de la técnica de composición, el poema se constituye en forma particular de cristalización de estas virtudes emergentes en la sociabilidad del salón, despreocupada de aspiraciones más altas. Son fragmentos, retazos de una cotidianidad contemplada en términos de entretenimiento, de ocio, también para el ejercicio de la poesía. Nada que ver con el empeño de construcción personal de Petrarca o de las tomas de posición de Lope. Para un autor como Enríquez de Cabrera ambas cosas le venían otorgadas por su nacimiento. Se trataba sólo de lucir sus galas, de recoger las piezas dispersas en los juegos de la galantería y el brillo social. Para ello no necesitaba firmar, ya que en el ámbito al que se dirigía los textos resultaban fácilmente identificables, y el autor podía mantener un aire de modestia o, incluso, de tópico desdén hacia un ejercicio que comenzaba a profesionalizarse. No renuncia, sin embargo, al cauce de la imprenta, y aun lo usa por dos veces, lo que viene a señalar la permeabilidad de los dos ámbitos, abriendo una puerta que sabrían usar muy bien unas décadas más tarde un escritor como Torres Villarroel o poetas como José Joaquín Benegasi y Eugenio Gerardo Lobo. Entre el humanista o el poeta soldado, convertidos en perfiles dominantes en la lírica quinientista, y la figura del profesional que inaugura Lope y va alcanzando auge creciente hasta principios del siglo XVIII, Enríquez de Cabrera, noble y cortesano, promotor de una anónima impresión y reimpresión de sus textos, encarna una figura que continúa la del noble amateur y la actualiza en la nueva sociabilidad, incorporando desde ella un nuevo factor en la dinámica de la poesía y la definición de su lugar en la nueva sociabilidad, en la que prima la distancia del poeta respecto de sus versos, piezas de ocasión, elementos del juego, mero instrumento de distinción mundana sin mayor pretensión de trascendencia, ni en el sentido de su discurso, ni siquiera en el de la caracterización del componedor como poeta sensu stricto.

Las composiciones surgen al hilo de la circunstancia y prácticamente permanecen ligadas a la misma, si no es por la extensión derivada del acceso a la imprenta. En la fijación tipográfica, que proyecta el poema fuera del tiempo y el espacio del salón donde nació y de la circunstancia que lo motivó, esta tiene que recuperarse en el rótulo, señal inequívoca de la necesidad de una clave para recomponer, siquiera en una medida parcial, el sentido del poema, que solo lo sostenía plenamente en el momento de su realización oral, en el contexto que le dio origen, con lo que tenía de muestra del ingenio y con el elemento añadido de la realización oral, de la actualización de su carácter eminentemente performativo. Es en este sentido en el que cabe hablar de poesía de circunstancia, en 
tanto la composición surge no por impulso de una fuerza interior, de una necesidad expresiva o de la construcción de un discurso coherente en sí mismo. Es fruto del ocio y, como tal, se reitera de manera fragmentaria, sin más aspiración a la variedad ni más preocupación por la cohesión textual que las derivadas del sucederse de las situaciones en un marco de cierta monotonía, demandante siempre de la sorpresa del ingenio. Como gran tema de la lírica, el amor se desliza a galanteo y se hace circunstancial, y la circunstancia es trivial. Una nueva dama en la reunión, un giro en la conversación, un reto galante y mundano dan pie a un cumplido o a la elaboración de un concepto, también en forma rimada, con el ejemplo perfecto del soneto. La demanda de entretenimiento y el tono que sustituía la rígida etiqueta cortesana anterior dan pie a la conversión en clave jocosa de las anécdotas del día, generalmente en forma de relación, para la que es especialmente dúctil el romance. Abandonado el mundo de las ideas, la realidad se muestra en su vertiente más cotidiana, apenas enmascarada por las convenciones del salón, camino de lo que será el buen gusto mundano ${ }^{33}$. Aún sin el rigor de la mirada científica que trasladan a España los novatores, la vista del hombre de mundo y de quien compone versos no se dirige a las alturas, sino que permanece más a ras de suelo, eso sí, el lujoso suelo del estrado de la dama o la brillante solería del salón, donde la despreocupación se hace posible y la circunstancia se reduce al plácido discurrir de la velada. Entre las prácticas permitidas no hay mucho espacio para el verdadero sentimiento, y, si no una razón ilustrada, lo que se extiende en versos como los considerados es una lógica de la mundanidad, una forma de racionalidad que surge de la mecánica racional del juego conceptista, sin la trascendencia epistemológica propuesta por Gracián, y que rechaza por igual la oscuridad y la excesiva llaneza, apostando, en palabras de Enríquez de Cabrera, por «la vereda que se entiende». Es el estilo que demanda el nuevo horizonte epistemológico, la sociabilidad del día y el lugar de una poesía sin voluntad de trascendencia, antes de convertirse también en la demanda de un creciente mercado editorial para la poesía. Tal vez podríamos habar de un estilo «razonable», de una musa sensata ${ }^{34}$, refractaria a las estridencias, incluidas la de lo sublime. Por esta vía la poesía adquiere una deriva que permitirá un engarce más fácil con la desarrollada por una ilustración temprana a la que aún le quedaban unas décadas para asentarse. Mientras tanto, el poeta en el salón vuelve la vista a los modelos altobarrocos para

33 Su proyección en las ideas sobre la poesía a lo largo del siglo XVIII es analizada por José CHECA Beltrán, Razones del buen gusto (Poética española del neoclasicismo), Madrid, CSIC, 1998.

${ }_{34}$ Podemos ver en esta dirección un precedente de la corriente estudiada por Elena de LoRENZo ÁLVAREZ, Nuevos mundos poéticos: la poesía filosófica de la Ilustración, Oviedo, Instituto Feijoo de Estudios del siglo XVIII, 2002. 
revisarlos y reelaborarlos en función de las nuevas expectativas. Sin duda, la lírica conocerá en este camino un fuerte proceso de alteración que la despoja de algunas de sus marcas identificadoras en la tradición anterior, como la sentimentalidad. Los riesgos de prosaísmo no siempre se sortearon de manera feliz. A cambio, el verso se dirigía a una modernidad en la que la razón reclamaba un lugar poético al lado del sentimiento. 